\title{
How not to respond to The X-Flles
}

\section{Belief in pseudo-science is a widespread problem. But some entertainment is misleadingly condemned in that} context, promoting the harmful image of the scientist as truth's ultimate custodian.

S cience is more than following laboratory protocols. It is about framing hypotheses and devising ways to shoot them down. It is about imagination, of daring to look up from what is known, and ask "What if?" - and then being able to work out the consequences.

That message is all too easily forgotten, sadly, by those who dismiss The X-Files as pernicious pseudo-science - and even by those who think more analytically about the television series, at least to judge from an article in the British newspaper The Independent (21 August) by John Durant, professor of the public understanding of science at Imperial College, London. As he says, surveys show that the public treats pseudo-science, such as astrology, more as a recreation than a truth to be believed. So why should we be worried about it? Durant thinks that popular fascination with pseudo-science is about the free market of ideas: in which case, he lightly suggests that there should be some kind of consumer organization to tell the public what is truth and what isn't, "checking out the performance of ideas and beliefs".

That notion does the public understanding of science more harm than good. It implicitly casts scientists as heartless, white-coated Gradgrinds with no capacity for imagination - yet scientists know that mental freewheeling is at the heart of their mission. How many rewarding experiments have come from kites flown in the coffee-room?

And now to The X-Files. For anyone who has missed it, The X-Files is a television drama series (and a movie) about a pair of FBI agents, Mulder and Scully, who investigate paranormal phenomena. Mulder's musings about aliens and suchlike are forever probed by Scully, who shows how the evidence in their casebook could have rational explanations. Very often, the results of their enquiries are inconclusive. The phenomena they observe could have a variety of interpretations, leaving the viewers to make up their own minds.

Is this deliberate looseness an unwitting laxity of plot? On the contrary, science is more like The X-Files than some detractors recognize. It can only progress darkly, up and down many blind alleys and false trails, from hypothesis to hypothesis. If that were not so, science would soon end. Perhaps as important, it invites participation, rather than enforcing the exclusivity of a secular priesthood of which the public would be rightly suspicious.

It is too easy to condemn The X-Files as "pseudo-scientific gibberish which would embarrass any self-respecting science-fiction writer" (as Durant polemically does). Again, that misses the point. Science fiction must follow the conventions of any other narrative or dramatic genre: it just so happens that just enough science (not too much) is added to the scenery to make it seem authentic. Yet the interaction of Mulder and Scully is as scientific as you please. They look at the evidence, they come up with hypotheses, they test them, and most are found wanting. Any truth that they think they find is soon undermined by new evidence that their preferred hypothesis cannot explain, and so they are forced to move on.

Why is The X-Files so popular? Partly, no doubt, because it responds (or, if you hate it, panders) to the general fascination for the obscure and inexplicable. But, thanks to science, today's oddball notion is tomorrow's orthodoxy. The existence of the inexplicable challenges us to question our hypotheses and, through investigation, extend them. The popularity of The X-Files suggests that the public clearly has more of a feeling for the spirit of scientific enquiry than some give it credit for. A rejection of the idea of custodians of truth does not reflect a preference for pseudo-science, but a dislike of being patronized.

The problem that remains is more general: that enjoying pseudoscience is a lot easier than enjoying science, especially if the latter, like the cod liver oil which is unpalatable but Good For You, is administered by a nanny. In the words of Mozart in the film Amadeus, who would not rather listen to their hairdresser than to Hercules?

\section{A chronic lack of definition}

\section{Tackling misconduct has been undermined by a lack of resolve of scientific advisers.}

t is now six years since the US National Academy of Sciences recommended a new regime of community self-regulation of scientific conduct, five years since the Congress established a Commission on Research Integrity to come up with something better, and three years this November since that commission, chaired by Kenneth Ryan, a former professor of obstetrics at Harvard, issued a report calling for new structures to investigate and adjudicate allegations of scientific fraud.

Ryan's findings found some favour among university administrators, who are currently saddled with what passes for authority over the problem, but were lambasted by scientific leaders. John Dingell (Democrat, Michigan), the bette noire of the US scientific community on this and other matters, had lost his bully pulpit at the head of the Commerce Committee in the House of Representatives in 1995, and the proposals died for lack of support in Washington.

As a correspondent writes on page 823 of this issue, the resultant impasse is undesirable. Yet it is set to continue until such time as a serious incidence of scientific misconduct reignites public concern on the issue. At the rate at which significant cases are arising (see, for example, page 817), that may not take too long.

President Bill Clinton's National Science and Technology Council was asked, in the aftermath of the Ryan report, to prepare a new and universally acceptable definition of scientific misconduct. It has now been sitting on this admittedly difficult problem for two-and-a-half years. It is high time that the council published its agreed definition, and demonstrated that the US government has the courage to tackle this serious problem. 